\title{
Escuta na relação médico-paciente: uma arte perdida
}

\section{Listening in the doctor-patient relationship: a lost art}

\section{Douglas Vinicius dos Santos Silva' 1 (1) Maria Gabriela Freitas Viana ${ }^{2}$ (1) Pedro Eduardo de Moura Souza ${ }^{3}$ (1)}

\begin{abstract}
1Autor para correspondência. Universidade do Estado da Bahia (Salvador). Bahia, Brasil. douglasvsantossilva27@gmail.com
\end{abstract} 2,3Universidade do Estado da Bahia (Salvador). Bahia, Brasil.viana.gabriela153@gmail.com, peduardomsouza@gmail.com

RESUMO | INTRODUÇÃO: A relação médico-paciente passou por várias reinterpretações no decorrer dos séculos, sendo pautada, primordialmente, na escuta atenta, característica que vêm sendo negligenciada em muitos contextos atuais. Tal relação médico-paciente se mostra fundamental para compreensão do quadro patológico em análise e, também, para o entendimento desse paciente como ser humano, o que atribuirá maior dignidade a esse momento tão íntimo, porém tão essencial na prática médica. Com isso, a literatura pode ser utilizada como uma ferramenta para incentivar o desenvolvimento humano dos profissionais e estudantes e, subsequentemente, a reflexão disso nessa importante relação. DESENVOLVIMENTO: Atualmente se percebe notável enfraquecimento da relação médico-paciente devido, principalmente, ao culto exacerbado do tecnicismo e depreciação do cultural, como os vários segmentos da literatura, quando, na verdade, cada um desses aspectos possuem seu espaço e devem se complementar. Tendo isso em vista, ocorre um maior distanciamento entre médico e paciente, o que acaba por prejudicar a imagem do exame clínico moldado pelo que deveria ser um coprotagonismo entre esses dois indivíduos. Devido a isso, o médico se torna cada vez mais insensível e, por conseguinte, o paciente se torna cada vez mais inalcançável, o que dificulta a devida promoção de saúde e futuro bem-estar desta pessoa. Assim, a literatura pode inserir-se como uma ferramenta que estimulará mudança desse contexto, seja pelo contato do médico com temas recorrentes no seu dia a dia a partir da visão de seus pacientes; seja pelo próprio autoconhecimento adquirido capaz de fazê-lo compreender a vulnerabilidade dos seres humanos, inclusive a sua própria. Ademais, outra importante função que a literatura pode propiciar é a de facilitar a própria coleta dos dados - por meio da linguagem ou até mesmo por ações realizadas pelo profissional - a qual terá desdobramentos importantes no prognóstico daquele paciente. CONCLUSÃO: Médicos e estudantes dessa área devem propiciar o maior conforto possível para o paciente que se encontra no estado de vulnerabilidade que a moléstia propicia e isso pode ser alcançado mais fácil e eficientemente com a utilização da literatura associada ao tecnicismo de maneira que se tornem complementares e abarquem os vários segmentos inerentes ao ser humano.

PALAVRAS-CHAVE: Relação médico-paciente. Educação médica. Literatura na medicina.
ABSTRACT | INTRODUCTION: The doctor-patient relationship has undergone several reinterpretations over the centuries being based on attentive listening primarily, a characteristic that has been neglected in many current contexts. Such a doctor-patient relationship is essential for understanding the pathological condition under analysis and, also, for understanding this patient as a human being, which will give greater dignity to this moment that is so intimate, yet so essential in medical practice. Thus, literature can be used as a tool to encourage the human development of professionals and students and subsequently reflect in this important relationship. DEVELOPMENT: Currently, there is a noticeable weakening of the doctor-patient relationship, mainly due to the exacerbated cult of technicism and the depreciation of the cultural, such as the various segments of literature, when, in fact, each of these aspects has its space and should complement each other. With this in mind, there is a greater distancing between doctor and patient, which ends up damaging the image of the clinical examination shaped by what should be a co-protagonism between these two individuals. Because of this, the doctor becomes increasingly insensitive and, therefore, the patient becomes increasingly unreachable, which hinders the proper promotion of health and future well-being of this person. So, literature can be inserted as a tool that will stimulate the change of this context, either by the contact of the doctor with recurring themes in his daily life from the perspective of his patients or by the acquired selfknowledge capable of making him understand the vulnerability of human beings, including his own. Furthermore, another important function that the literature can provide is to facilitate data collection itself - through language or even by actions performed by the professional - which will have important consequences on that patient's prognosis. CONCLUSION: Doctors and students in this area should provide the greatest possible comfort for the patient who is in the state of vulnerability that the disease provides, and this can be achieved more easily and efficiently with the use of the literature associated with technicism in a way which they become complementary and encompass the various segments inherent to human beings.

KEYWORDS: Doctor-patient relationship. Medical education. Literature in medicine. 


\section{Introdução}

A relação médico-paciente, desde a sua forma primária, fundamenta-se por meio de uma troca equilibrada entre falante e ouvinte. Nesse sentido, por envolver complexas dimensões socioemocionais, essa relação, por si só, pode ser considerada uma arte. Ao ter como princípio que os seres humanos são providos de particularidades individuais, observa-se que o aprimoramento desta performance artística é uma prática baseada em olhares atentos e contínua busca por adaptação.

Com o advento de formas mais rápidas e eficientes de diagnóstico, profissionais recentemente graduados tendem a perceber a conduta clássica de atendimento como uma tela do passado. Há séculos, as ferramentas que o médico dispunha eram apenas a história narrada pelo seu paciente e os achados em seu exame físico, cuja qualidade depende tão somente da destreza do profissional que o executa para encontrar os detalhes mais sutis. Então, munido destes poucos, porém efetivos, artifícios, o médico trabalhava de forma investigativa através da ligação entre pontos de interesse e da entrada nos cenários narrados pelo paciente para traduzi-los por meio de seu conhecimento técnico.

Nesse sentido, o momento no consultório era fortemente marcado por escuta, atenção ao sujeito à sua frente e pela criação de uma relação de confiança, aspectos que se revelam como as chaves para o processo de cuidar exercido pelo médico. Afinal, quando exames se mostram inconclusivos e imagens não são reveladoras, é somente voltando o olhar para o paciente e buscando sinais sutis na sua história que a resposta pode se revelar.

\section{Desenvolvimento}

Uma análise do contexto contemporâneo revela o enfraquecimento progressivo da confiança na relação estabelecida entre médico e paciente: enquanto o profissional simplesmente segue um roteiro pré-estabelecido, o paciente responde como se não estivesse realmente participando daquele processo como ser humano, mas apenas como uma pessoa que possui queixas que possam levar a alguma morbidade desconhecida.

A obra Doctor and Doll, de Norman Rockwell ${ }^{1}$, datada de 1929, ilustra o momento de uma consulta pediátrica na qual o médico aproxima seu estetoscópio de uma boneca da sua paciente. Na retratação, é evidente um dos aspectos mais brilhantes da atuação médica: a reinvenção, termo que extrapola o simples adaptar-se, estando relacionado à tentativa de aproximação e de estabelecimento de uma ponte entre dois mundos que, até então, desconheciam-se.

Figura 1. Doctor and Doll. Norman Rockwell (1929)

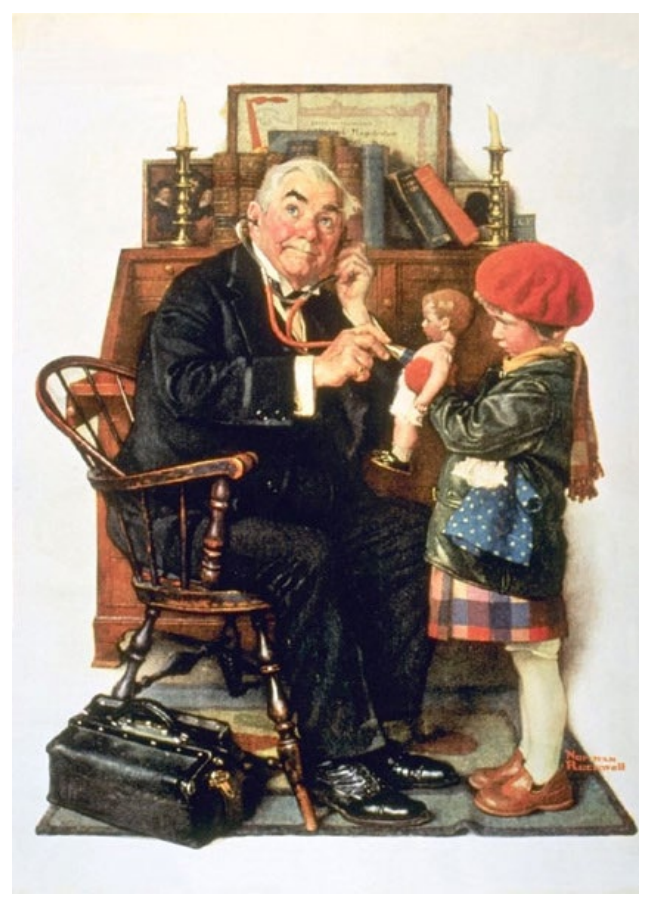

Fonte: https://www.wikiart.org/en/norman-rockwell/doctor-and-doll 
Um ato visto por alguns profissionais mais firmes e diretos como desnecessário, mas que constitui uma estratégia para manter aquela paciente confortável em face da sua presença. Esse tipo de artifício não se mostra necessário somente no atendimento direcionado à uma criança, haja vista que, por vezes, é preciso comentar sobre o placar do jogo da noite anterior, a visita em comum a determinada cidade e uma infinidade de outros temas que gerem proximidade e reconhecimento entre os sujeitos presentes no consultório. O momento vivido nesse ambiente, portanto, não se assemelha a qualquer outra entrevista. Nesse cenário, um roteiro de perguntas já memorizadas pode nortear o paciente quanto ao que o médico deseja ouvir, mas não contempla tudo aquilo que aquele expressa.

O contato com o paciente possui início e fim na linguagem e, por meio dela, esta aproximação consolida-se. Os mínimos detalhes devem ser observados: as palavras, os gestos, as sensações e os olhares, com 0 intento de perceber nas entrelinhas todos os significados carregados por cada palavra dita ou não dita. Por exigir conhecimentos técnicos e prática constante, ser capaz de realizar uma entrevista médica é uma habilidade adquirida que demanda contínua construção. Através disso, é evidente a importância de um permanente aprimoramento dos sentidos, aspecto que frequentemente é banalizado no ensino e na prática médica.

Diante da tentativa de impedir que a essência da medicina seja tomada pelo tecnicismo, observa-se a importância da transdisciplinaridade para a formação humanística do profissional. Basarab Nicolescu² preconiza que a transdisciplinaridade diz respeito ao que está entre, através e além das disciplinas, e objetiva, portanto, a compreensão do mundo presente. Afirma-se ainda que diz respeito a um "caminho de autotransformação, orientado para o conhecimento de si, para a unidade do conhecimento e para a criação de uma nova arte de viver." Através desta perspectiva, torna-se ainda mais notória a necessidade de adoção desse modelo de educação que se encarrega de abarcar todas as dimensões humanas. Dessa forma, a presença da área de humanidades, a qual inclui literatura, cinema, artes plásticas e visuais, mostra-se necessária durante a graduação médica com o intento de promover o desenvolvimento humano. A partir disso, é evidente que atuar na formação de um estudante resultará em um grande impacto na sua atuação como profissional.

Nessa perspectiva, a integração dessas áreas possui potenciais destacáveis. O primeiro é compreendido ao se refletir quanto à formação do profissional médico, como escreveu a médica e professora Lisa Sanders ${ }^{3}$ sobre a obtenção da história clínica do paciente:

Os médicos passam dois anos em salas de aula aprendendo a identificar e categorizar os processos patológicos, relacionando a entidades patológicas conhecidas. [...] pouquíssimos programas oferecem treinamento sobre como obter essas informações essenciais da pré-história do paciente. Ao que parece, supunha-se que isso não é algo que precisa ser ensinado.

Nesse contexto, tanto o consumo quanto a produção de textos literários e manifestações artísticas auxiliam no resgate do lado perceptivo, sensível e humano do profissional ou estudante. Lado esse que, indubitavelmente, o auxiliaria a construir uma nova lente pela qual ele enxerga o paciente e a sua história e que contribui para a percepção do nível de conforto do paciente ao conversar sobre determinado assunto.

No cenário conjunto entre medicina e literatura, uma das figuras que merecem destaque é o escritor João Guimarães Rosa, nascido no ano de 1908 e reconhecido por suas tentativas de desconstrução do abismo de mútua incompreensão existente entre a cultura científica e a cultura literária ${ }^{4}$. Em suas obras, é explícito o esforço despendido por Rosa para traduzir sensações que eram consideradas intraduzíveis. Por ser um médico de formação, grande parte da sua obra possui um enfoque em questões relacionadas à medicina e, especificamente, à relação médico-paciente, além de ter sido produzida com base na escuta de Rosa, não somente como médico, mas também como um ser humano de curiosidade ímpar. Um dos seus contos, Sorôco, sua mãe, sua filha ${ }^{5}$, explicita a descrição singular elaborada por Rosa para relatar uma doença psiquiátrica:

[...] A filha - a moça - tinha pegado a cantar, levantando os braços, a cantiga não vigorava certa, nem no tom, nem no se-dizer das palavras - o nenhum.

A moça punha os olhos no alto, que nem os santos $e$ os espantados, vinha enfeitada de disparates, num aspecto de admiração. 
Guimarães Rosa descreve o comportamento da doença psiquiátrica como um estágio de espírito mais elevado, semelhante a um encantamento. A descrição, portanto, que reflete a cultura popular permite o encontro entre ciência e literatura. Ao aplicar essa percepção no ambiente do consultório, o profissional passa a conectar-se com o seu paciente da forma mais precisa possível, facilitando o entendimento mútuo. No contexto da entrevista médica, são raros os momentos em que o paciente consegue traduzir aquilo que sente e, ainda mais raras, são as ocasiões em que o profissional consegue compreender aquilo que o seu paciente tenta explicar-lhe. A partir desses momentos, tornam-se ainda mais notórias as lacunas deixadas durante a formação médica, as quais, geralmente, são supridas por fontes que fogem à linearidade e precisão do conhecimento científico.

A literatura se insere no ensino e na prática da medicina como uma das alternativas que objetivam estimular competências ético-humanísticas, em um meio que tenta suprimir a dimensão biopsicossocial do médico e do paciente. Desse modo, a partir do universo literário, permite-se que o estudante se prepare para lidar com o paciente real através da aquisição da habilidade de interpretar experiências humanas ${ }^{6}$. Ademais, a literatura estimula o profissional a compreender os bastidores do desenrolar de uma doença. Sob essa perspectiva, a inserção da literatura no ambiente médico, aliada a uma metodologia ativa de ensino-aprendizagem contribuem para o incentivo à reflexão e auxiliam na formação de médicos que não se limitam e que possuem um campo de visão em constante expansão. Desse modo, ressurge a medicina voltada para o paciente: aquela capaz de percebêlo como um ser único de múltiplas dimensões ${ }^{8}$.

No que se refere às limitações dos seres humanos, sabe-se que são cidadãos de uma dupla cidadania, a qual se mostra dividida entre "o reino da saúde e o reino da doença" sistência, principalmente por parte da classe médica, em se reconhecer como vulnerável às diversas doenças. Nesse contexto, sempre optam por demonstrar o seu lado saudável, aspecto que acarreta o desenvolvimento de uma relação conturbada consigo mesmo ao optar por não reconhecer suas próprias limitações. Dessa forma, esse comportamento revela uma carência de autoconhecimento, a qual irá interferir negativamente na relação estabelecida entre o médico e o paciente por meio da eventual desumanização realizada pelo médico, tanto consigo quanto com o ser humano que necessita da sua assistência.

Durante e após a graduação, outro conhecimento mostra-se fundamental além do saber técnico e daquele advindo das experiências clínicas: o conhecimento a respeito da condição humana, a qual precede a dor e a doença, bem como revela caminhos capazes de lidar com ambas as situações ${ }^{8}$. Nessa perspectiva, as limitações remetem à condição humana e para compreendê-las, é fundamental que o profissional opte pelo autoconhecimento. O médico, portanto, no momento em que lida com suas experiências de sofrimento, capacita-se na arte do cuidado, além de permitir que seu paciente também se reconheça como um ser humano vulnerável e exposto aos processos de saúde-adoecimento.

\section{Conclusão}

O médico deve ser um ponto de tranquilidade no mar de angústias pelo qual seu paciente atravessa em um momento tão delicado e vulnerável. Sob essa perspectiva, a literatura pode ser utilizada de forma estratégica para o estímulo do desenvolvimento de um médico mais humano e, logo, melhor capacitado para atender as necessidades de seus futuros pacientes. Desse modo, a medicina passa a ser compreendida não como um estudo de doenças, mas sim como um estudo de seres humanos que pressupõe, portanto, equilíbrio entre técnica e sensibilidade, o qual pode ser alcançado através da inclusão de manifestações artísticas durante a graduação médica, as quais são produções essencialmente humanas.

\section{Agradecimentos}

Agradecemos às nossas orientadoras: lêda Maria Barbosa Aleluia, Maristela Rodrigues Sestelo e Nelma Arônia Santos por todo o apoio acadêmico e pelo conhecimento ofertado.

\section{Contribuições dos autores}

Silva DVS, Viana MGF e Souza PEM atuaram na concepção do projeto, coleta de referências, escrita, tradução e revisão do texto final. 


\section{Conflitos de interesses}

Nenhum conflito financeiro, legal ou político envolvendo terceiros (governo, empresas e fundações privadas, etc.) foi declarado para nenhum aspecto do trabalho submetido (incluindo, mas não se limitando a subvenções e financiamentos, participação em conselho consultivo, desenho de estudo, preparação de manuscrito, análise estatística, etc.)

\section{Referências}

1. Norman R. Doctor and Doll [Internet]. Wikiart; 1929. Disponível em: https://www.wikiart.org/en/norman-rockwell/doctor-and-doll

2. Nicolescu B. A Evolução Transdisciplinar na Universidade: Condição para o Desenvolvimento Sustentável [Internet]. Centre international de recherches et études transdisciplinaires. Disponivel em: https://ciret-transdisciplinarity.org/bulletin/ b12c8por.php

3. Sanders L. Todo paciente tem uma história para contar: Mistérios médicos e a arte do diagnóstico. Rio de Janeiro. Editora Jorge Zahar; 2010.
4. Goulart EMA. O viés médico na literatura de Guimarães Rosa. Faculdade de Medicina da Universidade Federal de Minas Gerais; 2011.

5. Rosa JG. Primeiras Estórias. 6a. ed. Rio de Janeiro: Editora José Olympio; 1972.

6. Balbi L, Lins L, Menezes MS. A Literatura como Estratégia para Reflexões sobre Humanismo e Ética no Curso Médico: um Estudo Qualitativo. Rev. bras. educ. med. 2017;41(1):152-61. https://doi. org/10.1590/1981-52712015v41n1rb20160049

7. Sontag S. Doença como metáfora. Vol. 6. Rio de Janeiro: Editora Graal; 1984.

8. Torres RF. O curador-ferido e a individuação. Revista da Sociedade Brasileira de Psicologia Analítica [Internet]. 2018;36(1): 49-58. Disponível em: http://pepsic.bvsalud.org/scielo. php?script=sci_arttext\&pid=S0103-08252018000100008

9. Scliar M. Literatura e medicina: o território partilhado. Cad. Saúde Pública. 2000;16(1): 245-8. http://dx.doi.org/10.1590/S0102$311 \times 2000000100026$

10. Porto CC. A entrevista clínica não é uma conversa como outra qualquer! Rev Med Minas Gerais. 2016;26: e-1806. http://dx.doi. org/10.5935/2238-3182.20160106 